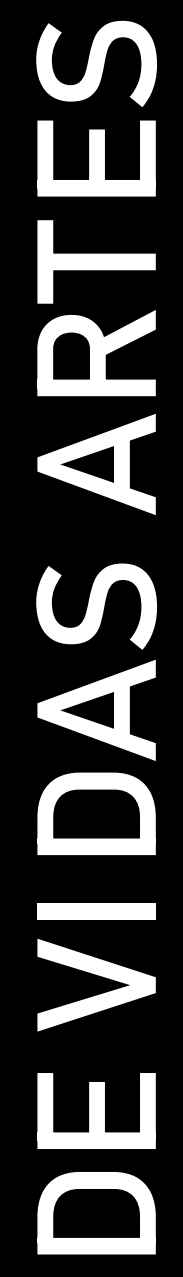

PAULA GUERRA E LÍGIA DABUL (EDS.) 


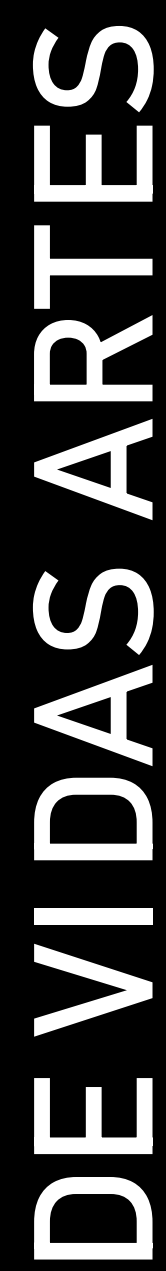

\section{PAULA GUERRA E LÍGIA DABUL (EDS.)}

Design por Irandina Afonso

Ilustração da Capa por Lua Celina

Publicado em Setembro 2019

Universidade do Porto. Faculdade de Letras

[University of Porto. Faculty of Arts and Humanities]

Porto, Portugal

ISBN 978-989-8969-18-7

Suporte: Eletrónico - Formato: PDF / PDF/A 


\title{
II.4. Cidades, gestos, imagens em provoc-ações
}

\section{II.4. Cities, gestures, images in provoc-actions}

\section{Elenise Andrade}

\section{Resumo}

Este capítulo aborda o projeto de pós-doutoramento "Provoc-ações: (des)ocupar imagens, (des)enquadrar escritas, perambular por Bahias e Portos" realizado na Universidade do Porto. Buscamos aproximações entre educação e conceitos da filosofia da diferença pela via das visualidades. Oficinas entendidas como momentos de fazer/pensar imagens - e não procedimentos analíticos pretendendo identificar o que 'elas representam, explicam, registram'. Três instituições escolares portuguesas abrigaram as Oficinas, auxiliando-nos sobre o questionamento: Que linhas-fios (des)escrevem as cidades pelo funcionamento diagramático gesto-corpo-signo? Em cada uma das instituições, um artefato cultural a (des)contar sobre cotidianos, sensações, conhecimentos. Funcionamento diagramático por entre cidades a intensificar linhas, cores, luzes, sombras, estudantes, professores.

Palavras-chave: imagem, filosofia da diferença, arte, educação escolar.

\begin{abstract}
This chapter is about the postdoctoral project "Provocations: (dis) occupy images, (dis) framing writings, wandering through Bays and Ports" that was developed in the Faculty of Arts of the University of Porto. We seek approximations between education and philosophy of difference's concepts through visuality. Workshops understood as moments of making / thinking images - not analytical procedures intended to identify what 'they represent, explain or record'. Three Portuguese school institutions housed the Workshops, helping us to think about: Which lines (dis) write the cities by the diagrammatic gesture-body-sign operation? In each of the institutions, a cultural artifact to (dis) tell about every day, sensations, knowledge. Diagrammatic operation between cities to intensify lines, colors, lights, shadows, students, teachers.
\end{abstract}

Key words: image, philosophy of difference, art, schooling.

\section{Atraversar}

\section{OU}

\section{A menina de lá}

E ela, menininha, por nome Maria, Nhinhinha dita, nascera já muito para miúda, cabeçudota e com olhos enormes.

Não que parecesse olhar ou enxergar de propósito. Parava quieta, não queria bruxas de pano, brinquedo nenhum, sempre sentadinha onde se achasse, pouco se mexia. - "Ninguém entende muita coisa que ela fala..." - dizia o Pai, com certo espanto. Menos pela estranhez das palavras, pois só em raro ela perguntava, por exemplo: - "Ele xurugou?"-e, vai ver, quem e o quê, jamais se saberia. Mas, 
pelo esquisito do juízo ou enfeitado do sentido. Com riso imprevisto: - "Tatu não vê a lua..." - ela falasse. Ou referia estórias, absurdas, vagas, tudo muito curto: da abelha que se voou para uma nuvem; de uma porção de meninas e meninos sentados a uma mesa de doces, comprida, comprida, por tempo que nem se acabava; ou da precisão de se fazer lista das coisas todas que no dia por dia a gente vem perdendo. Só pura vida (Guimarães Rosa, 2001: 67-68).

Estórias absurdas que nos atravessam e ao Oceano Atlântico ${ }^{108}$. Tatu não vê a lua. Quem vê? A menina de lá? Gestos, expressões, parênteses, hífen, cores a nos convidarem a uma mobilização da vida ordinária. Ninguém entende muita coisa que ela fala... Uma porção de atraversações entre imagens, cidades e conceitos deleuzianos percorrerão esse texto, quase como uma precisão de se fazer lista das coisas todas que no dia por dia a gente vem perdendo. Uma vontade de (des)educar a educação por atraversamentos a funcionarem politicamente, nos termos de Rancière (2012: 60):

A política é a prática que rompe a ordem da política que antevê as relações de poder na própria evidência dos dados sensíveis. Ela o faz por meio da invenção de uma instância de enunciação coletiva que redesenha o espaço das coisas comuns.

Subversões, resistências, residências, urgências. Esse texto traz provoc-ações imanadas do projeto de pós-doutoramento "Provoc-ações: (des)ocupar imagens, (des)enquadrar escritas, perambular por Bahias e Portos" desenvolvido com a supervisão de Paula Guerra no Departamento de Sociologia na Universidade de Letras da Universidade do Porto. A (des)ocupação e o (des)enquadramento proposto nesse projeto de pesquisa também vem acompanhado das incursões das pesquisadoras Alda Romaguera e Alik Wunder (Wunder \& Romaguera, 2014; Romaguera \& Wunder, 2016) em momentos de encontros e criação junto a imagens e letras e palavras e fios junto às oficinas que realizam no desenvolvimento do projeto de pesquisa "In-ventos por entre áfricas, literaturas e imagens":

Composições, sobreposições e disjunções entre fragmentos de livros, poemas rasgados, ilustrações e fotografias. Contingentes e potentes encontros entre poemas e imagens num jogo de experimentação fotográfica e escrita. [...] As foto-escritas experimentais derivam de exercícios de mixagem que se in-ventam a cada encontro, movidos pela pergunta: o que podem as palavras frente à força das imagens? Extrair da palavra sua significação, fazê-la vibrar, é um dos desafios quando se cria um espaço de experimentação coletiva. (Romaguera \& Wunder, 2016: 129-130).

\footnotetext{
${ }^{108}$ Este capítulo aborda o projeto de pós-doutoramento da autora intitulado "Provoc-ações: (des)ocupar imagens, (des)enquadrar escritas, perambular por Bahias e Portos" realizado na Universidade do Porto Departamento e Instituto de Sociologia sob a orientação científica da Professora Doutora Paula Guerra.
} 
Para o desenvolvimento dessa pesquisa, visitamos três instituições escolares com a proposta de que os estudantes fissurassem a vontade de (re)cognição de cidades, deixando-se contaminar pela vontade de entender, sentir, explorar, inventar a cidade não apenas como cenário, mas sim que se desenhe como máquina produtora de signos, expressão, conhecimentos, "outros modos de ver, de maquinar e de magicar" (Godinho, 2016: 33). Esse capítulo buscará, a partir deste cenário, arrastar a arte para fissurar os controles fixadores e possibilitar emergir os lugares-sensações através de uma afecção. Explorando, por meio desta proposta de pesquisa-intervenção, formas de partilha que envolvem (outros) modos, implicando uma ideia de efetividade do pensamento (Rancière, 2012). Pensar/expressar a arte não como um modelo formatado de conhecimento, mas aceitar uma invasão de fluxos, potências, estremecimentos.

A arte como nutrição e potência para que não sejamos formatados pelos poderes a nos censurarem os pensamentos e as sensações, expulsando palavras de ordem a pré-definir e classificar o que é passível de ser visto e admirado, em detrimento de nossas pequenas e sensíveis vivências pelos espaços e tempos que experienciamos. Apostamos, aqui, em uma proposta junto ao pensamento de O'Sullivan (2009), para quem a prática artística contemporânea não oferece mais do mesmo, não produz 'conhecimento', não proporciona um reconfortante espelho refletindo uma subjetividade já estabelecida. Tais artistas seriam, portanto, um tipo de profetas traidores, "[...] na medida em que realizam uma traição em relação aos nossos regimes afetivos/significantes mais dominantes (isto é, a realidade consensual)" (2009: 248). Trair o consenso, a comunicação junto a uma palavra de ordem. - "Nhinhinha, que é que você está fazendo?" - perguntavase. E ela respondia, alongada, sorrida, moduladamente: - "Eu... to-u... fa-azendo." Fazia vácuos. (Rosa, 2001: 68). Explorar vacúolos de comunicação, em uma movimentação gesto-corpo-signos em momentos de produção de imagens em três instituições portuguesas localizadas em cidades pertencentes à região da Porto, Portugal.

Invenções incomuns pelos espaços das vidas ordinárias, que de tão comuns, muitas vezes frágeis, gesticulam em singularidades que promovem a existência. Não uma promoção pela comunicação, por uma linguagem de acordos e consensos, mas na experiência, na impossibilidade de um entendimento puramente cognitivo. "Se a experiência estética toca a política, 
é porque também se define como experiência de dissenso, oposta à adaptação mimética ou ética das produções artísticas com fins sociais". (Rancière, 2012: 60) Afecções.

Ampliar as linhas e os pensamentos dos signos emitidos arriscandonos com Deleuze e o funcionamento do diagrama quando o filósofo, ao atraversar a obra de Francis Bacon, propõe que o pintor, em seus quadros, desafia a figuração e a narração. Aspectos que, para Deleuze (2007), são efeitos que teimam em invadir os quadros (não somente os de Bacon). Esse desafio desata fios e linhas e forças - o diagrama. Assim, experimentamos, junto a esse conceito, tencionar o que chamamos de 'política representacional', manifesta na insistência em uma delimitação estrita da verossimilhança, priorizando um modelo hierarquizante de comunicaçãorecognição, produzindo poucas possibilidades de multiplicação de sentidos para os fenômenos, os objetos, as imagens, as escritas, a vida, o mundo.

Cidades, gestos, imagens emissoras de signos. Godinho (2007), quando traz Deleuze (2003) e o conceito de signo, nos lembra:

Os signos artísticos (...) têm um 'poder' sobre todos os outros. Poder esse que Ihes vem da possibilidade de introduzirem um Tempo que não existe nos outros signos, que opera transformações das matérias e dos materiais. (Deleuze, 2003: 20).

Cais, praias, vazios, azulejos, cidades em funcionamento diagramático, intensidades a forçarem o movimento criativo e inesperado do pensamento, da proliferação de sentidos. Em um borramento entre ficção e realidade a cidade se nos apresenta como uma paisagem-sonho a ser percorrida sem pressa, ex-pressão a pulsar em cotidianos múltiplos, efêmeros, intensivos. Nosso objetivo, portanto, não se detém em comparações, explicações sobre o que tal imagem representa, qual(is) conhecimento(s) pode $(m)$ ser detectado(s), mas desejar, nos encontros com os estudantes, professores e imagens, cidades que escapam, se contorcem, desmoronam de uma representatividade e que nos provocam a questão de pesquisa: Que linhas-fios (des)escrevem as cidades pelo funcionamento diagramático gestocorpo-signo? 


\section{Perambular}

\section{OU}

Uma menina está perdida no seu século à procura do pai

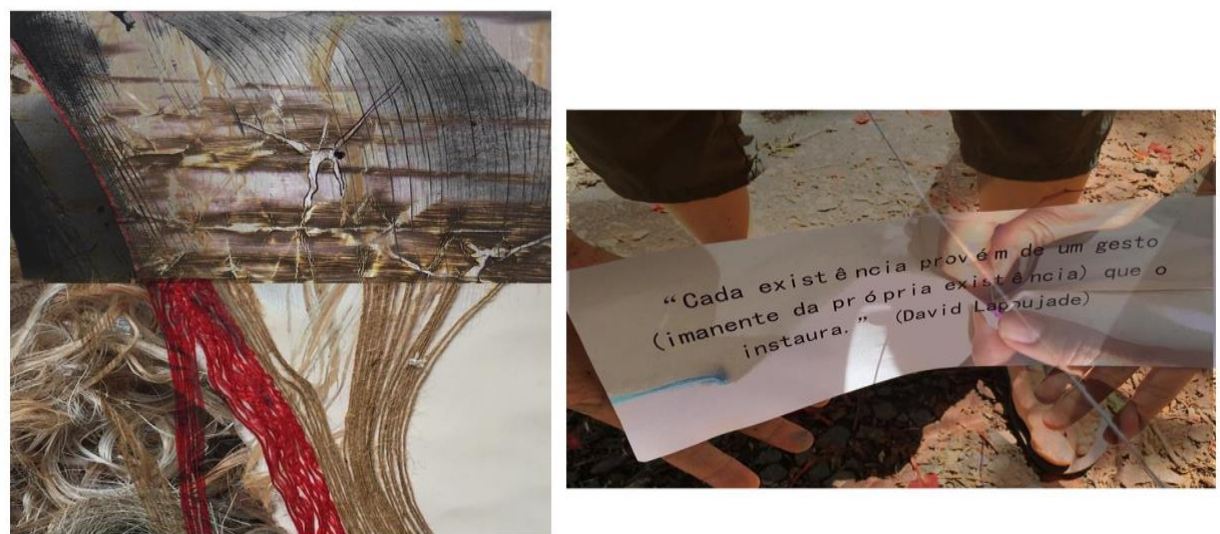

Figuras II.4.1: Des-fios

Fonte: Fotografias de autoria de Marli Wunder postadas em sua conta pessoal no Instagram.

Des-alinhar... Vagabundear. Perder-se pelos séculos. Deslocar-se de 'seu tempo. Escutar os fios. Venha, menina, tocar os corpos, ver com a pele, ouvir com os dedos. Sensações perturbadoras? Cotidiano perturbador? Estar perdida e procurando alguém não seria tão perturbador quanto? Mas não seriam as perturbações gestos de um cotidiano vivo $\mathrm{e}(\mathrm{m})$ experiência? Perambular pelo funcionamento da expulsão de uma necessidade de explicação e (re)cognição dos limites olhos-tato-ouvidos-cidadespensamentos. Gestos-signos que nos inspiraram a uma metodologia da pesquisa em experimentações.

Signos-diagramas convidando-nos a recusar a investida na produção de sistemas homogêneos de pensamento que atravessam imagens, textos e sons na contemporaneidade e, para isso, assumir o conceito de diagrama como proposta de exploração das potencialidades intensivas dos/nos signos a nos impelir a explorar uma zona de fissura. Imagens produzidas provocando um mundo-signo ao experimentar-se junto às ficções, fazendo fugir um cotidiano que se coloca como presente ou registro de um passado (Andrade \& Bastos, 2017). Estar aberto aos pequenos e delicados gestos, quase (in)visíveis, quase (in)tocáveis, entendidos com Lapoujade (2017: 15) como a

maneira de fazer existir um ser em determinado plano. [...] Cada existência provém de um gesto que o instaura, de um 'arabesco' que determina que será tal coisa. Esse gesto não emana de um criador qualquer, é imanente à própria existência. 
Deslimitar uma metodologia de pesquisa em escritas não comunicáveis que, atraversada pelos gestos, apresente-se como uma "comunicação de uma comunicabilidade" (Agamben, 2015: 60). Gaguejar, balbuciar. Como desentender a escrita, a linguagem, para potencializar a fissura, o caos e nos lançar aos vestígios dos gestos-corpos-signos da cidade? A escolha pelos procedimentos e posturas metodológicas aqui apresentados já nos atravessam desde 2014, quando iniciamos o projeto de pesquisa As cidades (des)enquadradas em imagens: experimentações (atra)versando o conceito de signo ${ }^{109}$, envolvendo Oficinas ${ }^{110}$ no Colégio Estadual Aristides Cedraz (CEACO), Ichu, no sertão baiano, com aproximadamente 20 estudantes que, em 2014, cursavam o primeiro ano do ensino médio. Experimentamos um conceito de Oficina como momentos de experimentação, onde provocamo-los, com o auxílio de várias obras artísticas a eles apresentadas, a in-ventarem imagens da cidade que transgredissem a política da representação, para, então, possibilitarem a imersão em uma lógica das sensações, pulsações de lugares recortados pelo instante de um clique sob o olhar deslocado do fotógrafo (Almeida, 2015).

Arrastar essa vivência espaço-temporal para os encontros ocorridos com os estudantes portugueses. Gestos-signos em expansão, e não procedimentos analíticos pretendendo identificar $o$ que as imagens 'representam', 'o que elas querem dizer', 'o que explicam e registram'. As Oficinas se apresentam como exercício de criação por meio de uma aproximação com o campo da arte no intuito de provocar o campo da educação. Imagens e pensamentos que nos instigam a questionar: o que podem as imagens quando não pretendem explicar, ilustrar, registrar as cidades? (Andrade, Almeida \& Brandão, 2017).

Propomos, na pesquisa aqui apresentada, uma ampliação desses procedimentos em outras (des)ordens, linhas de potência em gestos imperceptíveis. Funcionamento maquínico no re-a-linhar o pensar a sensação

\footnotetext{
109 Projeto aprovado pelo Edital MCTI/CNPq/MEC/CAPES No 43/2013, coordenado por Elenise Cristina Pires de Andrade, Universidade Estadual da Feira de Santana.

${ }^{110}$ As oficinas sempre ocorreram na escola, envolvendo aproximadamente 20 estudantes que, em 2015, data da primeira oficina, cursavam o segundo ano do ensino médio. Tais encontros duraram cerca de duas horas, sendo realizadas em 17/04; 12 e 22/05 de 2015, nessa última contamos com a presença de Alik Wunder, professora da Faculdade de Educação da Unicamp, que também compõe a equipe de pesquisadores deste projeto. No ano de 2016 tivemos as oficinas em 17/06, quando trabalharam com vídeos produzidos por professores de Florianópolis, sob a coordenação de Davi Codes e Leandro Belinaso, da Universidade Federal de Santa Catarina (mestrando e professor, respectivamente) e a última ocorreu com a artista Marli Wunder, em 26/08.
} 
para o plano educação desconsiderando movimentos que levem a concretizações, centralidades e determinações seja da ciência, da arte, do tempo, da produção de conhecimento ou do próprio pensamento. Outras formas de partilha em (des)ocupações, (des)enquadramentos.

Provoc-ações. Fios-palavras em uma intimidade quase exposta. Gestos. Imagens que escorrem. Aposta no caos das linhas do diagrama, funcionamento imprevisível, investindo nas possibilidades táteis dos olhos, visuais do ouvido. Pele que escreve, orelhas que enxergam. Afecções a encurvar os pilares e os ditames da educação em um funcionamento do gesto a desorganizar o consenso, a implodir uma busca estrita da recognição, fissuras na política de pensar o já pensado. Fios-linhas enquanto potentes forças diagramáticas em imagens e escritas que desmancham a cidade e suas maquinarias. Que gestos (des)ocupariam essas cidades-diagramas? Que não são nem reais nem fictícias, mas uma cidade em devir, imprevisível e infinitamente potente...

\begin{abstract}
Para que o diagrama funcione, para que ele seja diferente de um simples esquema, é preciso que ele revele o sentido das suas singularidades. E é porque o diagrama está sempre na interface do actual e do virtual que ele pode assegurar a passagem de um a outro por uma maquinaria que é a alma do diagrama. Essa maquinaria não está lá para representar objetos, mas para produzir, no real, uma actualização das suas componentes virtuais, revelar ao mundo sensível uma face inédita do objeto. (Godinho, 2013: 141).
\end{abstract}

Esvaziar dados já dados de antemão. Desfazer os dualismos. Não perguntar o que esses gestos mostram da/na/com a cidade, mas o que as intensidades e forças que a atravessam e povoam querem nos mostrar... Gestos-linhas. "Difícil é não haver um mundo à nossa espera para ser criado, é estar no meio" (Godinho, 2016: 33). Deslocar, desclassificar. Pensamentos desejantes em desequilibrar fronteiras fixas entre imagem, ficção e realidade; conhecimento e explicação; educação, arte e criação, indo em busca de um modo, um funcionamento do gesto. Intensidade do instante.

Propomo-nos: pensar com potências que nunca são más nem negativas, com forças novas e desconhecidas, forças sem palavras e, com elas, sem imagens e com milhões de imagens a passar sem cessar, sempre com sons e gritos não sonoros, sensações e afectos alegres que penetram de forma assignificante todos os corpos. (Godinho, 2016: 34).

Por onde transitaria uma vontade de assignificar o plano 'educação' numa (des)ocupação? Propomos uma postura no desmanchar-se em possibilidades e ampliações de provoc-ações, multiplicação de sentidos atraversando imagens, borrando a fixidez do traço-palavra, do pixel-luz, perderse em qualquer século, (s)em busca. (Des)aproximações das imagens do 
plano estrito do registro e da veracidade através de vivências de um cotidiano (Andrade 2012, 2015, 2016). Uma menina...

Aproximei-me do microscópio e olhei pela sua lente. O primeiro choque fez dançar as letras de um lado para o outro, mas de imediato se fixaram e li: 'NÃO DIRIGIR A PALAVRA AO NOSSO PÓ'.

Afastei o olho do microscópio, desviei a cabeça e olhei de novo para a folha [...] Perguntei-Ihe [a Agam, o escritor da 'linha'] se ele conseguia ler a linha, foram mesmo essas as palavras que eu usei: Consegue ler a linha sem o microscópio? Claro, respondeu.

- Não consigo escrever a linha sem o microscópio e sem os meus utensílios de pormenor, mas consigo ler, sem qualquer problema (Gonçalo M. Tavares, 2015: 152-153).

\section{Provoc-ações (des)montadas}

\section{OU}

\section{A menina quebrada}

Catarina estava aterrorizada. "A menina... A menina..." Ela continuava repetindo. Olhei para os lados e demorei um pouco a enxergar o que ela tinha visto em meio a tanta gente. Uma garota de uns 12 anos, talvez, com uma perna engessada. "Quebrou..." Catarina repetia. "A menina...quebrou." (Eliane Brum, 2013: 425).

Provocar fissuras no movimento escreverpesquisar até quebrar, aterrorizar. Desmontar. Talvez não conseguir escrever uma linha sem os utensílios, mas ser tocado pela possibilidade de leitura! Que Porto poderia ser inventada, conhecida, sentida, expressada pelos gestos fotográficos dos estudantes envolvidos nessa pesquisa? Alunos de três instituições de ensino: Escola Artística de Soares dos Reis (12.ํano) localizada na cidade do Porto; Escola Superior de Artes e Design (ESAD), alunos de graduação da Licenciatura em Comunicação situada em em Matosinhos e, em Gondomar, alunos do 7. ano de Percurso Curricular Alternativo ${ }^{111}$ da Escola Básica dos 2.ํ e 3.. Ciclos de Fânzeres. As aproximações com essas instituições ocorreram durante os meses de dezembro de 2017 e maio de 2018, sempre com a participação dos professores e professoras envolvidos com as diferentes turmas e a proposta de produção de imagens dos lugares vivenciados cotidianamente por parte dos estudantes. Em cada uma das instituições, um artefato cultural 'final' expressou os gestos provocados com as atividades.

O percurso mais prolongado aconteceu junto a turma da Escola Artística de Soares dos Reis, uma classe de 20 alunos do Curso de Produção

\footnotetext{
111 "Os Percursos Curriculares alternativos (PCA) são uma medida de promoção do sucesso educativo, no ensino básico. Trata-se de uma oferta específica de natureza complementar a outras existentes tendo em vista a inclusão social e o cumprimento da escolaridade obrigatória." Fonte: http://www.dge.mec.pt/percursos-curriculares-alternativos
} 
Artística $^{112}$, na especialização "Têxteis" ${ }^{113}$, notadamente com o objetivo de promover a arte têxtil contemporânea, suas técnicas e materiais, trazendo o passado até aos nossos dias, continuando com as explicações da professora Cristina, com que desenvolvemos todo o trabalho na escola. A ideia da professora foi incrível, já que ela propôs para a turma um projeto que envolvesse as "Narrativas de viagem"114 no percurso casa-escola-casa através de fotografias. A apresentação desse projeto iniciou-se com Álvaro de Campos: "afinal, a melhor maneira de viajar é sentir". Sensações por paisagens expressivas de seus cotidianos. Após essa etapa, as estudantes construíram um conceito acerca dessas experiências a fim de planejar um artefato escultural (com dimensões máximas de $50 \mathrm{~cm}$ x $50 \mathrm{~cm}$ ) usando pelo menos três técnicas têxteis. Em junho de 2018 essas esculturas foram expostas na Fundação Escultor José Rodrigues.

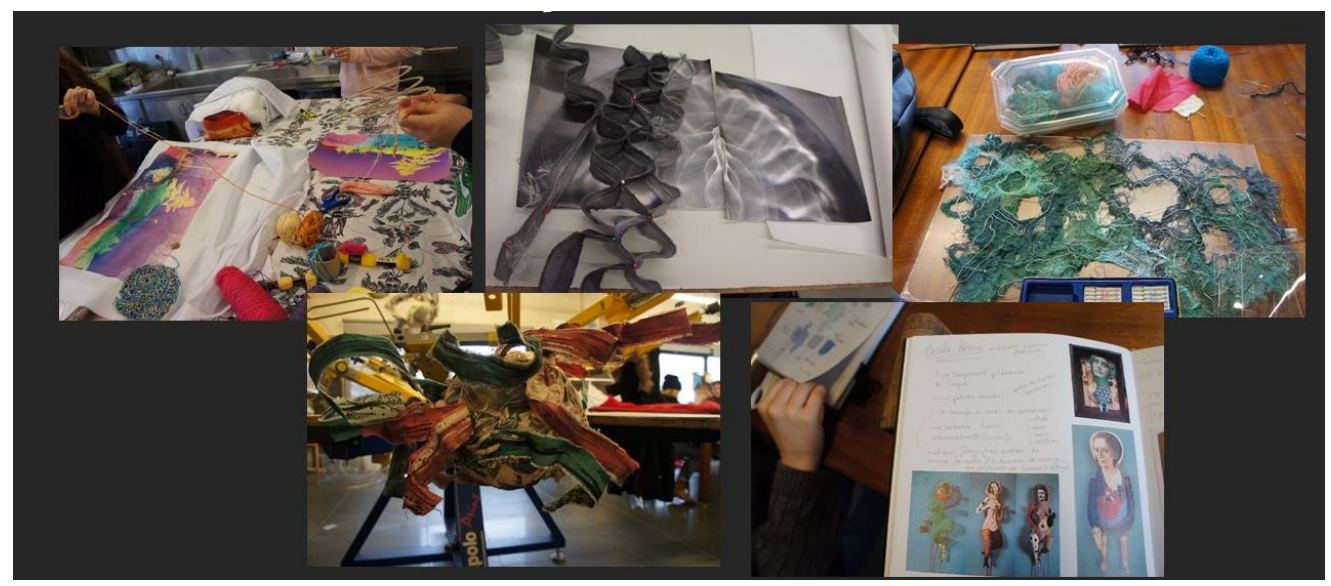

Figura II. 4. 2: Momentos de produção das esculturas têxteis na Escola Artística de Soares dos Reis em 2018

Fonte: Fotografias do arquivo pessoal da autora.

O encontro com graduandos da Licenciatura em Comunicação na ESAD (Escola Superior de Artes e Design) em Matosinhos ocorreu durante 3 aulas do professor Luís, docente da disciplina optativa para o terceiro ano, "Fotografia" e, em sua maioria, estudantes pertencentes ao Erasmus ${ }^{115}$. A

\footnotetext{
112 Maiores informações disponíveis no site da Escola: https://producaoartistica5.wixsite.com/easr-pa.

${ }^{113}$ Maiores informações disponíveis no site da Escola: https://producaoartistica5.wixsite.com/easr-pa/copiaceramica.

114 "Viaje na sua viagem diária. Pretende-se que cada aluno observe o seu percurso casa-escola, escolacasa e faça um registo fotográfico deste. É importante que, nesse registo, contenha imagens de pessoas, edifícios (arquitetura), paisagens, texturas, objetos, movimentos, sensações, sombras... imagens que traduzam o vosso quotidiano e o vosso percurso. Procure informações sobre os sítios que percorre diariamente. Devem sobressair nos vossos registos a multiplicidade de perspetivas e sensações que exprimem a vossa rotina."

115 "A internacionalização da escola remonta à sua fundação. Passa pelo intercâmbio ERASMUS, pela mobilidade de estudantes, professores e pessoal técnico, pela divulgação de projetos académicos e pela
} 
proposta foi a de apresentar para os alunos o projeto de pesquisa e, logo em seguida, solicitar a produção de fotografias da cidade do Porto para a produção de um fanzine. Para o convite aos estudantes, formulei os seguintes questionamentos: Qual é a cidade (do Porto)? Como podemos compreendê-la? Que visões não posso ver? Que sons não posso ouvir? Que ações podemos provocar para desestabilizar visões e sons do Porto produzidos enquanto perambulo pelas ruas? Que imagens podemos (não) ocupar através deste movimento? Que escritos podemos (des)enquadrar nesta viagem?
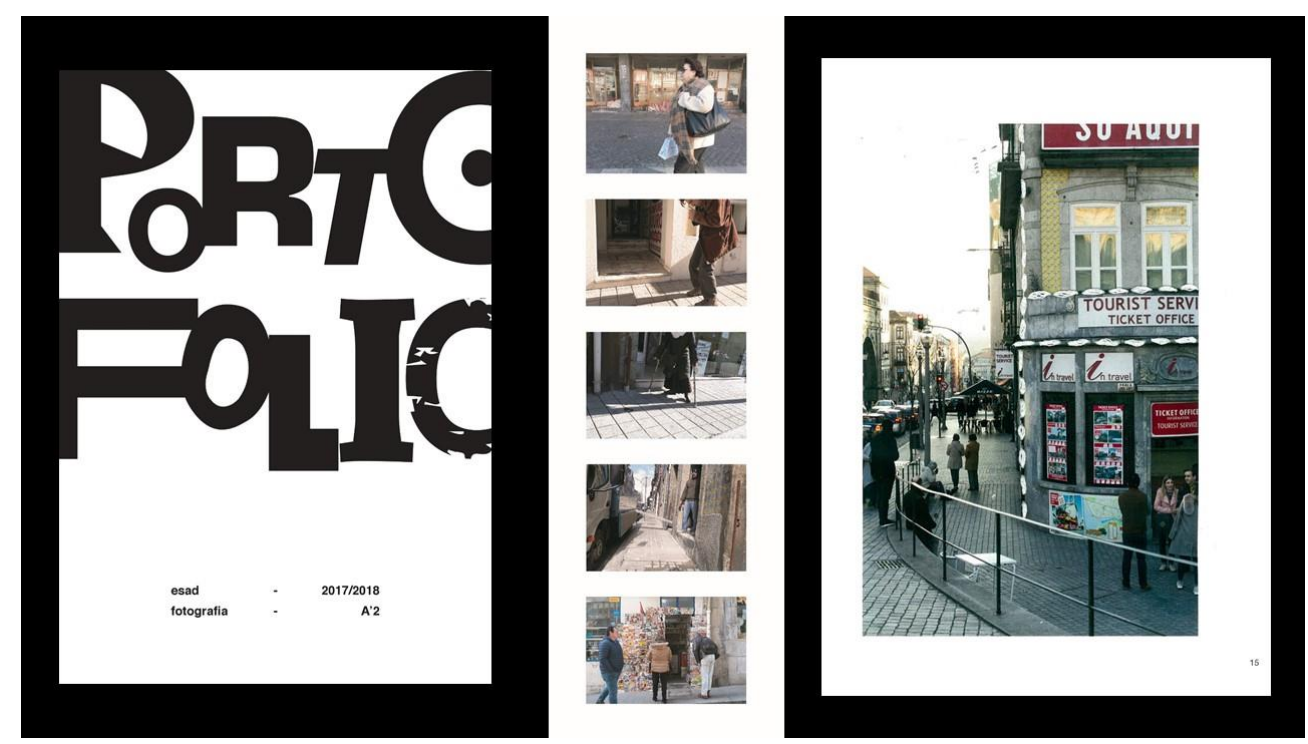

Figuras II. 4. 3: Páginas do fanzine - ESAD Fonte: Fotografias do arquivo pessoal da autora.

A última instituição a ser visitada localiza-se em Gondoma. Encontramo-nos com alunos do 7.. ano de Percurso Curricular Alternativo ${ }^{116}$ da Escola Básica dos 2.ํ e 3. Ciclos de Fânzeres. Nossas atividades aconteceram durante a disciplina de Português, e a professora e coordenadora Ana Paula me colocou em um grupo privado na rede social Facebook contando com 17 estudantes. Tivemos uma interessante interação com a produção de muitas fotografias que serviram de suporte para um

realização de eventos e publicações de design. Atualmente, a ESAD tem parcerias e contratos bilaterais com cerca de 150 instituições de ensino superior dos cinco continentes. (Fonte: https://esad.pt/pt/escola)

116 "Os Percursos Curriculares alternativos (PCA) são uma medida de promoção do sucesso educativo, no ensino básico. Trata-se de uma oferta específica de natureza complementar a outras existentes tendo em vista a inclusão social e o cumprimento da escolaridade obrigatória." Fonte: http://www.dge.mec.pt/percursos-curriculares-alternativos 
trabalho formal solicitado pela professora, que foi apresentado na classe em forma de um arquivo power point.

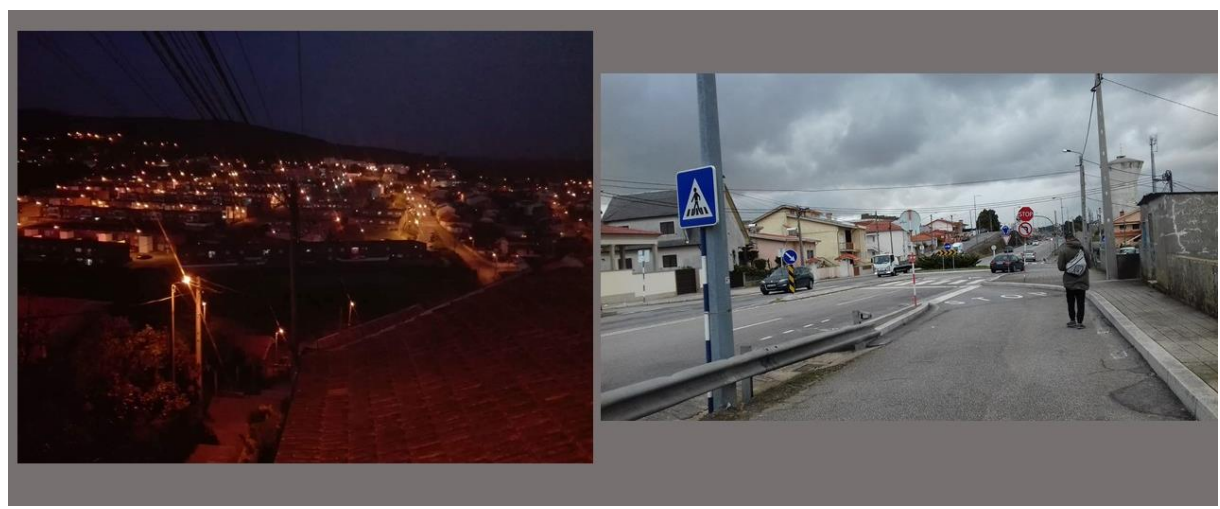

Figuras II. 4. 4: Fotografias dos percursos cotidianos dos estudantes na Escola Básica dos 2..ำ 3.ำ ciclos de Fânzeres em 2018

Fonte: Fotografias do arquivo pessoal da autora.

\section{4. $F(r)$ iccionar}

OU

\section{A menina sem palavra}

"[...] recolocar o texto como um espaço-tempo de experimento de imaginação, um campo de montagem. A ficção permite-me assumir a não transparência da escrita sem, entretanto, dispensar a alteridade, quer pelo risco de autoencapsulamento, quer por riscar da paisagem os diversos modos pelos quais a diferença distorce, desloca, faz derivar e constitui a escrita da pesquisa. Thiago Ranniery, 2018

Ficcionar como condição da pesquisa conferir alteridade a uma força animada e movente de corpos e objetos, como propõe Ranniery (2018), gestos a gestarem expressões (s)em educação. "Permitir que a ficção teça processos educativos significa criar fissuras, lidar com o inesperado, fruir entre conteúdos e sensações, procurar pelo dado novo (dentro e fora da imagem), revelar aos olhos aquilo que não se vê." (Leite, 2017: 30)

Fricionar um pensamento flâneur sobre-com as cidades, as imagens, os corpos. Mobilização da vida ordinária, pulsante, a esparramar-se em gestos de re-existência, signo-gesto na radicalidade da política. Corpos intensivos. "O que caracteriza o gesto é que, nele, não se produz nem se age, mas se assume e suporta" (Agamben, 2015: 58). Multipli-cidades a ocuparem cores, conceitos, formas, esculturas. Expressões que se estendem a outros movimentos de expansão, gestando contágios entre cidades, ruas, paredes, olhos, mãos. Contaminações através de gestos estéticos para arrastar a resistência política provocando um intenso afeto para desestabilizar o 
pensamento. (Des)educar uma educação na/com a afecção, em uma enunciação redesenhada para um espaço das coisas comuns, como nos traz (Rancière, 2012). Lugares-sensações à medida que caminhamos pelas rachaduras e interstícios da criação em re-existências das cidades do Porto, Matosinhos e Gondomar.

Narrativas de viagem a desestabilizar o narrável no sentido da linearidade e justificativa de que houvessem fios delimitadores entre realidade e ficção; certo e errado; ação e pensamento. Esculturas têxteis que foram esculpidas a partir de conceitos criados pelas alunas em contato com as imagens produzidas cotidianamente. Na obra Plantei edifícios, a aluna assim justifica suas escolhas:

o meu conceito dirige-se para o passar do tempo em função da rotina. No nosso quotidiano passamos por edifícios que têm história sendo estes agora apenas a fachada de algo que antes foram. Isto adequa-se à nossa rotina pois com o passar do tempo o quotidiano de hoje será mais tarde uma mera memória. Sendo assim associo os edifícios antigos à rotina.
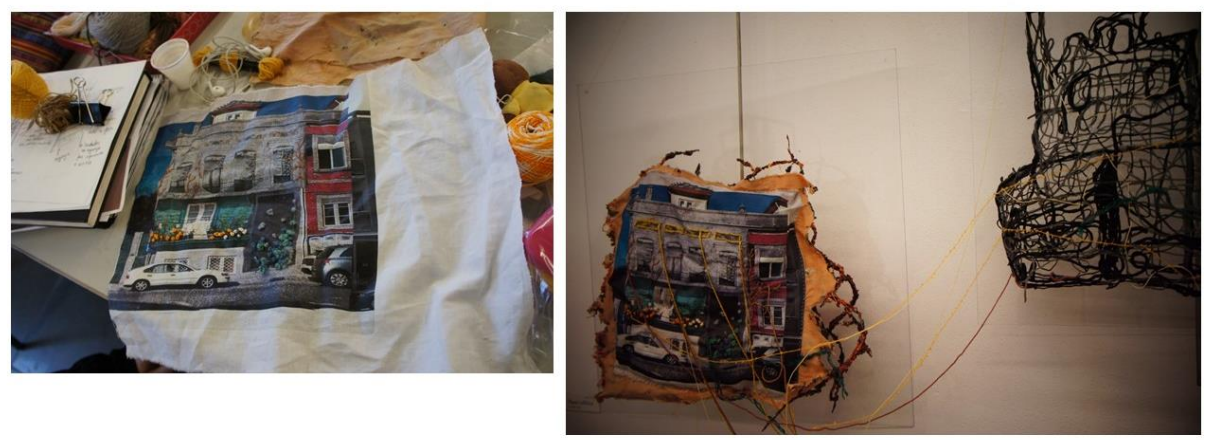

Figuras II. 4. 5: Fotografia à esquerda: momento de confecção da escultura têxtil. Fotografia à direita: Exposição da mesma escultura no Fundação Escultor José Rodrigues em 02/06/2018

Fonte: Fotografias do arquivo pessoal da autora.

Tempos móveis, memórias em expansão pelos fios coloridos que (des)ligam a imagem à estrutura de metal vazada. Vazio que instaura a intensidade de vida por um cotidiano aiônico, não cronológico, a explorar diferentes manufaturas junto às imagens e expressões. Menina, que fiospalavras! Desa-fios a fissurarem a representacionalidade da fotografia, assim como as discussões para a ordenação das fotografias para o portofolio, o fanzine dos estudantes da ESAD. Cores, saturação, e os azulejos como fios a atraversarem a produção. Uma estudante focou sua viagem pelas letrasfios de neon. Noite a possibilitar as expressões das letras. Bailar pelas ruas, palavras que se desligam de suas rígidas significações e se soltam... Outra 
menina... outra palavra. Outras palavras, como canta Caetano Veloso: "Nem vem que não tem, vem que tem coração tamanho trem/ Como na palavra, a palavra, palavra estou em mim"117.
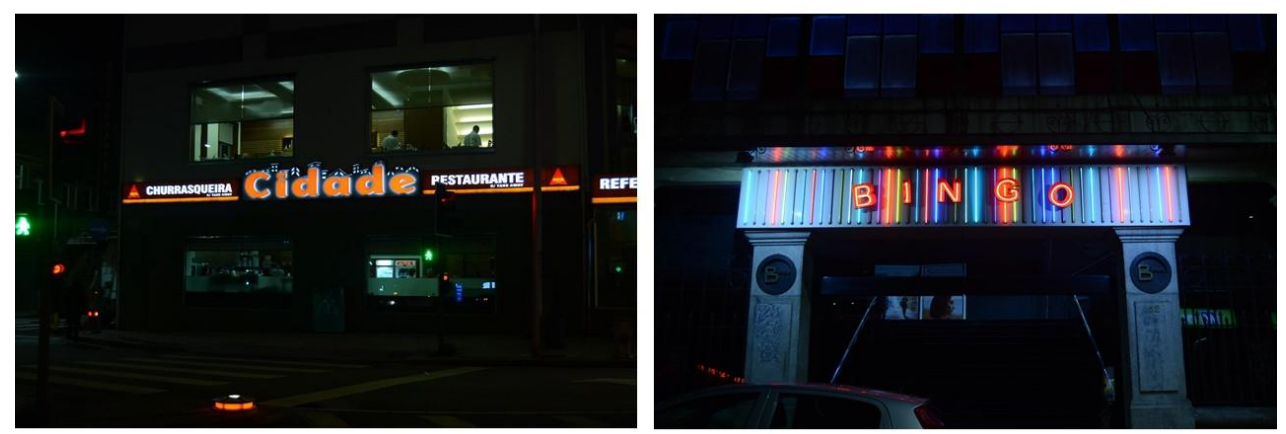

Figuras II. 4. 6: Fotografias apresentadas por uma estudante da ESAD para composição do fanzine

Fonte: Arquivo enviado pela aluna durante as Oficinas.

(Des)ocupações em escritas a pretenderem ex-critas, quase escritas, quase ex-critas. Ex criptas em resistências às armadilhas do mundo que tanto nos fascinam, como nos diz Ana Godinho (2016). Injetar luzes de neon por caminhos impensáveis, com/desde dentro de linhas de escritas as cidades e suas superfícies, sejam peles, muros, janelas, imagens.
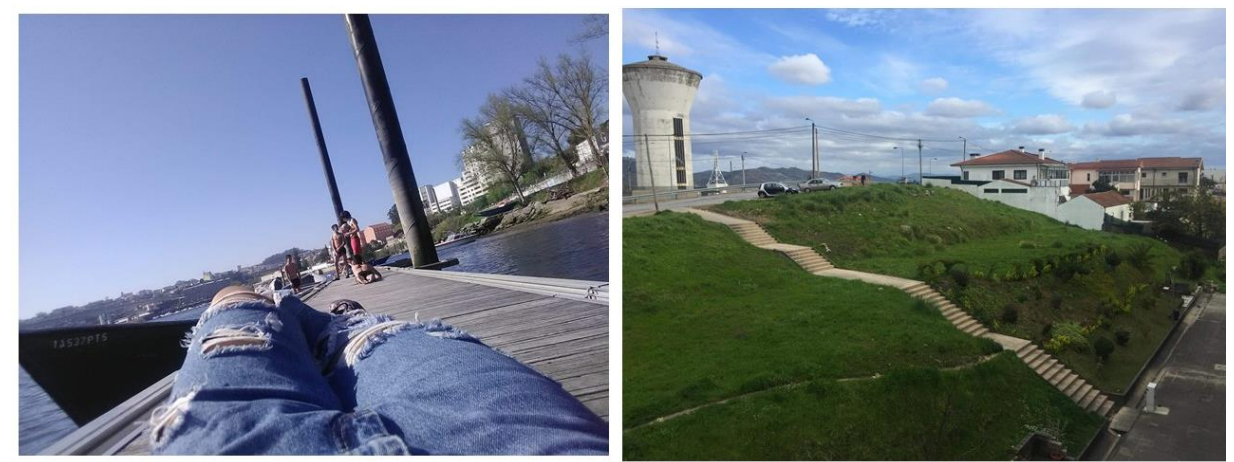

Figuras II. 4. 7: Fotografias apresentadas por uma estudante da Escola Básica dos $2 .{ }^{\circ}$ e $3 . \circ$ ciclos de Fânzeres para discussão no grupo privado do Facebook

Fonte: Arquivo enviado pela aluna durante as Oficinas.

Tramar pelas cores, pela calça jeans, pelas escadas, pelas (des)atenções. Des-narrar (Andrade \& Romaguera 2011; 2012). Alunos do sétimo ano, em condições de atenção especial, já que a maioria vive em situações de vulnerabilidade e já vivenciou a grade curricular do sétimo ano mais que uma vez. Corpos-gestos quase imperceptíveis, alijados de uma

117 Música Outras palavras, de Caetano Veloso, lançada no álbum de mesmo nome de 1981. 
condição de cognição mas que se esparramam pelos lugares-sensações a que foram provados. Outra menina sem palavra?

\begin{abstract}
A menina não palavreava. Nenhuma vogal Ihe saía, seus lábios se ocupavam só em sons que não somavam dois nem quatro. Era uma língua só dela, um dialecto pessoal e intransmixível? Por muito que se aplicassem, os pais não conseguiam percepção da menina. Quando lembrava as palavras ela esquecia o pensamento. Quando construía o raciocínio perdia o idioma. Não é que fosse muda. Falava em língua que nem há nesta actual humanidade. (Couto, 2013: 33)
\end{abstract}

Como não esquecer o pensamento quando lembramos a palavra, menina? Portos, Matosinhos, Gondomares. Signos em gestos. Desfocar na nitidez. Tempos-espaços a fissurar um plano-cenário para as cidades e entendê-la, senti-la explorá-la como uma máquina produtora de expressões e conhecimentos. (Des)crevê-la com a potência de uma ex-crita que não mais se escreve? O que nos permitiria (e às cidades) perceber existências frágeis, exigentes de forças caóticas e poderosas, no limite da enexistência, conquistar uma existência mais intensa? ${ }^{118}$

Vontade de escrever sem escritas, sem letras. Gaguejar no sentido de esgarçar de tal forma os dualismos que eles se des-com-sub-vertam em fios. Des-afiar.

Os dualismo não se referem mais a unidades, e sim, escolhas sucessivas: você é um branco ou um negro, um homem ou uma mulher, um rico ou um pobre, etc.? [...] Há sempre uma máquina binária que preside a distribuição dos papeis e que faz com que todas as respostas devam passar por questões pré-formadas, já que as questões são calculadas sobre as supostas repostas prováveis segundo as significações dominantes. Assim se constitui uma tal trama que tudo o que não passa pela trama não pode, materialmente ser ouvido (Deleuze \& Parnet, 1998: 29).

Em cada uma das instituições, um artefato cultural a (des)contar sobre o cotidiano, sobre as sensações, as andanças, os movimentos, os conhecimentos... Força vital, funcionamento diagramático por entre cidades de ambos os lados do Atlântico e, neste ritmo gaguejante, intensificar linhas, cores, luzes, sombras, estudantes, professores. Per-correr em busca de linhas escreventes, que, talvez nem tenham a pretensão de serem lidas, com ou sem utensílios. Em qualquer século. Aterrorizando os gessos que não remendam. Não procurar um trajeto narrativo, mas forças em devires. Perambulação, uma flânerie que quer abordar outros flâneurs, que caminham

\footnotetext{
118 "São provavelmente as existências mais frágeis, próximas do nada, que exigem com força tornarem-se mais reais. É preciso ser capaz de percebê-las, de apreender seu valor e sua importância" (Lapoujade, 2017: 41).
} 
sem rumo, uma deliciosa perda de tempo cronológico para mergulhar no aion. Abandonar as certezas que, porventura, ainda se efetivem nessa pesquisa.

(Des)ocupar cidades, (des)enquadrar escritas. Potência dos fragmentos em gestos em devir. Que potências outras estéticas e políticas surgiriam $d(n)$ esse perambular? Quais gestos invadiriam as cidades em um devir intensivo provocado por signos a nos forçar atraversar o impensável; a provocar fendas no movimento maquínico da enunciação nos muros, nas ruas, nas fotografias, nas palavras, disparando forças criativas; a ressoar por gestos em afecção?

\section{Referências Bibliográficas}

Agamben, G. (2015). Meios sem fim: notas sobre a política. Belo Horizonte : Autêntica Editora.

Almeida, E. C. (2015). Que Ichu (des)enquadra em mim? Revista Alegrar, v. Dez/2015, n. 16, 2015.

Andrade, E. C. P. \& Bastos, L. M. S. (2017). Gestos imperceptíveis: cidades em (des)ocupações... (des)territorializações. Leitura: Teoria \& Prática. 35(69), 137-155. Retrieved from https://ltp.emnuvens.com.br/ltp/article/view/553

Andrade, E. C. P. \& Romaguera, A. (2012). Currículos versam escritas(-)pesquisas. Currículo sem Fronteiras, 12 (3), pp. 153-172.

Andrade, E. C. P. (2012). D(ex)sloc-ar. Leitura: Teoria \& Prática, Campinas, 30 (59), pp. 86-100. Acedido em: http://ltp.emnuvens.com.br/ltp/article/view/25/25.

Andrade, E. C. P. (2015a). Sinfonia em AR menor: transversAR, (des)cartAR, ex-pressAR. Remea, Special, 20-37. Acedido emhttps://www.seer.furg.br/remea/article/view/4848

Andrade, E. C. P. (2016). Ocupações (im)prováveis: que cidade devém? Revista ETD, 18(3), 651-669. doi: https://doi.org/10.20396/etd.v18i3.8644678

Andrade, E. C. P.\& Romaguera, A. (2011). Sonhar-te e(m) vidas. (Des)narr-ar... Revista Rua, 17(1).

Andrade, E. C. P., Brandão, E. A. \& Almeida, E. C. (2017). Gestos (im)prováveis: ocupações e(m) afecções... Revista Teias, 18(51), pp. 101-114.

Brum, E. (2013). A menina quebrada. In A menina quebrada e outras colunas de Eliane Brum. Porto Alegre: Arquipélago Editorial.

Couto, M. (2013). A menina sem palavra. In A menina sem palavra. São Paulo : Boa Companhia.

Deleuze, G. \& Parnet, C. (1998). Diálogos. Trad. Eloisa Araújo Ribeiro, São Paulo : Escuta. 
Deleuze, G. (2003). Proust e os signos. (A. Piquet \& R. Machado, Trads.). Rio de Janeiro: Forense.

Deleuze, G. (2007). Francis Bacon: lógica da sensação. Trad. Roberto Machado (coord.) Rio de Janeiro: Jorge Zahar.

Godinho, A. (2013). Diagramas para pensar/diagramas de sensação. In Gallo, S., Novaes, M. \& Guarienti, L. B. O. (Orgs). Conexões: Deleuze e políticas e resistências e... Petrópolis, RJ: DP\&A; Campinas, SP: ALB; Brasília, DF: Caés.

Godinho, A. (2016). Máquinas anómalas e nómadas: do que ainda não existe ao que já não existe mais. Ou do que já não existe mais ao que ainda não existe. In Romaguera, A. \& Amorim, A. C. (Org.). Conexões: Deleuze e máquinas e devires e... (pp. 27-36). Rio de Janeiro: DP et Alii.

Godinho, A. (2007). Linhas de estilo: estética e ontologia em Gilles Deleuze. Lisboa : Relógio D'Água Editores.

Lapoujade, D. (2017). As existências mínimas. Trad. Hortência Santos Lencastre. São Paulo : $\mathrm{n}-1$ edições.

O'Sullivan, S. (2009). From Stuttering and Stammering to the Diagram: Deleuze, Bacon and Contemporary Art Practice. Deleuze Studies, 3(2), pp 247-258.

Rancière, J. (2012). O destino das imagens. (M. C. Netto, Trad.). Rio de Janeiro: Contraponto.

Romaguera, A. R. T. \& Wunder, A. (2016). Políticas e Poéticas do Acontecimento: do silêncio a um risco de voz. Revista Brasileira de Estudos da Presença. 6(1) 124-146. doi: http://dx.doi.org/10.1590/2237-266051077

Rosa, J.G. (2001). A menina de lá. In Primeiras estórias. Rio de Janeiro : Nova Fronteira.

Tavares, G.M. (2015). Uma menina está perdida no seu século à procura do pai. São Paulo : Companhia das Letras.

Wunder, A. \& Romaguera, A. R. T. (2014). Experimentações Coletivas por Entre Poesias, Fotografias e Ventos-Áfricas. Informática na Educação: teoria e prática,17(2), pp. 3145. 